\title{
UN LIBRO SOBRE LA ESCUELA NORMAL SUPERIOR
}

\author{
Gonzalo Cataño \\ Universidad Pedagógica Nacional
}

Quiero agradecer a las directivas de la Universidad Pedagógica Nacional la invitación a participar en el lanzamiento del libro de los sociólogos históricamente orientados, Martha Herrera y Carlos Low sobre la Escuela Normal Superior. No dudo en calificar esta obra de notable contribución al conocimiento de la educación nacional y a la difusión de uno de los esfuerzos más acabados y significativos que ha tenido el país en relación con la formación de docentes para la enseñanza media.

Los intelectuales y el despertar cultural del siglo: el caso de la Escuela Normal Superior, muestra con suficiente detalle las dificultades que acompañaron la vida de esta meritoria institución. En sus escasos 15 años de vida, la Escuela Normal apenas logró evadirse de las tensiones políticas de su entorno. Creada en 1936 por la innovadora administración de López Pumarejo, murió en 1951 como fruto de la reacción conservadora que caracterizó las decisiones del gobierno de Laureano Gómez en materia de educación.

Desde un principio los fundadores de la Escuela Normal orientaron la formación de docentes a partir de criterios modernos. Subrayaron, en primer lugar, la enseñanza de las ciencias. A su juicio, los profesores de la enseñanza secundaria deberían estar familiarizados con las complejidades de una disciplina científica. Si elegían la química, la lingüística, la historia o la geografía, deberían conocer las dificultades de sus corpus teórico y no reducirse a informaciones de compendio y de meras generalidades. Deberían estar en capacidad de dar cuenta del desarrollo de su especialidad, pero sobre todo y muy especialmente, de sus marcos de referencia, de su cuerpo abstracto, sistemático y operativo de conocimientos. Como una derivación de esta estrategia, buscaban, en segundo lugar, inculcar en los estudiantes una actitud positiva hacia la investigación. Para los animadores de la Normal era claro que un docente extraño a la obtención de nuevos conocimientos no llenaba las demandas de un mundo marcado por la innovación, el cambio y las transformaciones en las esferas de la cultura, la economía y la organización social.

Al lado de estos énfasis, la Normal difundió desde un comienzo lo mejor del pensamiento pedagógico contemporáneo: la transmisión del conocimiento mediante la experiencia, la práctica y la unión de la teoría y los hechos. En este proceso sus regentes fueron claros en afirmar que la manera más acabada de enseñar una asignatura era conociéndola, pues quien domina un campo específico de la actividad humana lo transmite a otros con relativa facilidad. De allí el énfasis permanente en las ciencias básicas que acompañó los mejores días de la Normal. Para sus representantes más conspicuos la pedagogía era un saber que se ocupaba de los fines de la educación y de los métodos más adecuados para transmitir el acervo de conocimientos, pero en ningún momento reemplazaba la formación básica del docente. 
Esta estrategia pedagógica dio lugar a los mejores productos de la Escuela Normal. De ella salieron las primeras generaciones de científicos sociales colombianos que después desarrollaron una importante labor en los campos de la antropología, la lingüística, la geografía y la historia. Martha Herrera y Carlos Low muestran con claridad y persuasión los logros académicos de sus egresados y su contribución a la organización de los estudios sociales y humanísticos en nuestro medio. Por los predios de la Normal pasaron el historiador Jaime Jaramillo Uribe, los antropólogos sociales Virginia Gutiérrez, Alicia Dussán y Roberto Pineda, los arqueólogos Eliécer Silva Celis y Luis Duque Gómez, los lingüistas Luis Flores y Aristóbulo Pardo, el geógrafo José Agustín Blanco y el crítico literario Gustavo Correa. Y en uno de sus establecimientos anexos —el Instituto Etnológico Nacionalcomenzó su obra uno de los antropólogos que más contribuciones ha hecho a la arqueología y etnología nacionales, el austríaco de nacimiento y colombiano de adopción, Gerardo Reichel-Dolmatoff.

Con dominio de su tema, los autores describen el nacimiento, el desarrollo y la decadencia de la Escuela. Sus profesores y estudiantes, los planes y programas, sus recursos académicos y la vida cotidiana de la institución. La Normal logró reunir en su tiempo una de las bibliotecas universitarias más ricas del país. Según los autores, su fondo alcanzó los 50.000 volúmenes, una extensión considerable para la época, sobre todo cuando se recuerda que en 1994 los recursos bibliográficos de una de sus herederas —la Universidad Pedagógica Nacional— sólo llegaba a los !26.000 volúmenes!

Una vez disuelta la Normal en 1951, la formación de docentes para la enseñanza secundaria perdió todo espíritu científico. Las múltiples Facultades de Educación que surgieron a finales de la década del cincuenta y comienzos de los años sesenta -incluyendo las dos prolongaciones de la Escuela, la Pedagógica de Tunja y la Pedagógica de Bogotá-, centraron sus esfuerzos en la docencia y en la formación moralizante del maestro. Con ello abandonaron el aspecto más dinámico de la vida universitaria, y sus profesores y estudiantes quedaron reducidos a una rutina pedagógica asociada con las didácticas. En sus claustros los docentes se olvidaron de la investigación y los vínculos con las disciplinas científicas se limitaron a la lectura de compendios y textos generales extraños a toda actitud inquisitiva y por principio ajenos a la vanguardia del conocimiento. Esto fue llevando a las Facultades de Educación a ser calificadas por los colegas de las demás carreras profesionales, de socios menores del sistema universitario. Su nivel académico comenzó a ser objeto de estigmas, y las oportunidades ocupacionales de sus egresados se fueron limitando hasta alcanzar salarios que apenas se diferenciaban de los montos obtenidos por los grupos más estables de la clase obrera.

Si la historia tiene alguna utilidad, el libro de Herrera y Low nos traslada a otras épocas para iluminar los problemas de nuestro tiempo. Su relato registra la experiencia de una institución y las soluciones dadas a sus retos. Es un acierto, además, que el volumen haya sido publicado por la Universidad Pedagógica Nacional; así tendremos mayores oportunidades de saber cuánto nos hemos alejado del patrón que nos dio vida, pues de persistir en el énfasis actual, estaremos en peligro de formar profesores que saben enseñar química y geografía, pero que apenas conocen los rudimentos de las ciencias de Lavoisier y de Vidal de la Blache.

Deseo felicitar una vez más a los autores de este libro y recomendar su lectura a las personas comprometidas con las decisiones y las políticas educativas. Ellas no tendrán, por 
lo demás, ninguna dificultad en hacerse al contenido de sus capítulos; la escritura de Herrera y de Low es clara y directa y el lector avanza sin dificultad a través de sus páginas. A diferencia de la prosa oscura y espesa de la mayoría de los analistas educativos de nuestros días, los autores de este libro conocen las trampas del lenguaje y saben que la sencillez de la exposición es el mejor adorno de las ciencias sociales. 